and one in each group was receiving bDMARD. M1 circulating monocytes were expanded in RA as compared to HI. This difference was at RA-CV (+) expense. RA monocytes had higher Intracellular levels of IL-1b and IL-6 as compared to HI. M1 from RA-CV (+) had higher intracellular levels of IL-1b and IL-6 than RA-CV (-). M1 monocytes have higher levels of inflammatory cytokines than M2. P-S6R protein, (mTORC activation), was higher in RA patients than $\mathrm{HI}$. The highest levels of P-S6R was observed in M1 monocytes from RA-CV(+) population.

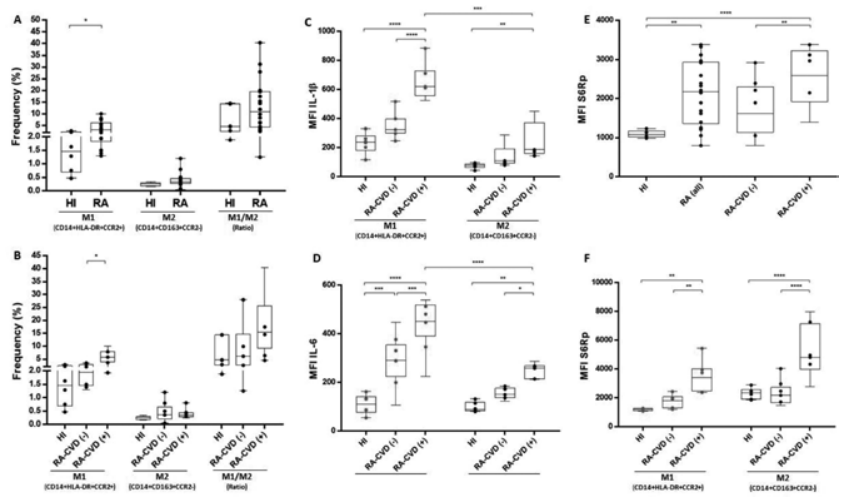

FIGURE 1. Circulating monocytes phenotype, intracellular cytokines and phosphorylated S6R in $\mathrm{HI}$ and RA-CV (+), RA-CV (-) and the combined RA patients.

A) ${ }^{*}=0,02$; B) ${ }^{*}=0,016$; C ${ }^{\star * \star *}=0,0001,{ }^{* \star}=0,002$; D) ${ }^{\star \star * *}=0,0001,{ }^{* \star *}=0,0008,{ }^{* \star}=0,001,{ }^{*}=0,01$; E) $\left.{ }^{\star \star * *} 0,0001,{ }^{* \star}=0,002 ; \mathrm{F}\right){ }^{* \star * *}=0,0001,{ }^{* *}=0,001,{ }^{* \star}=0,003$.

Conclusion: RA-CV+ patients, have a significantly higher number of pro-inflammatory circulating monocytes, using a multiparametric classification method. These monocytes also express higher levels of inflammatory cytokines and higher activation of $\mathrm{mTORC}$, which also participate in the development of atheromatous plaque, suggesting that these monocytes could be a key element in the non-clarified-yet, excess of CV risk of RA patients.

References:

[1] Fukui S, et al. M1 and M2 Monocytes in Rheumatoid Arthritis: A Contribution of Imbalance of M1/M2 Monocytes to Osteoclastogenesis. Front Immunol. 2017;8:1958.2. Zhuang J, et al. Comparison of circulating dendritic cell and monocyte subsets at different stages of atherosclerosis: insights from optical coherence tomography. BMC Cardiovasc Disord. 2017 Oct 18;17(1):270.

Disclosure of Interests: None declared

DOI: 10.1136/annrheumdis-2020-eular.6645

\section{SAT0005 INHIBITION OF HEPATOCYTE GROWTH FACTOR/C- MET SIGNALING ABROGATES JOINT DESTRUCTION BY SUPPRESSING MIGRATION OF MONOCYTES TO SYNOVIUM IN RHEUMATOID ARTHRITIS}

M. Hosonuma ${ }^{1,2,3}$, N. Sakai ${ }^{2,3}$, H. Furuya ${ }^{1}$, Y. Tsubokura ${ }^{1}$, S. Nishimi ${ }^{1}$, Y. Ikari ${ }^{1}$, S. Ishii ${ }^{1}$, A. Maeoka ${ }^{1}$, T. Tokunaga ${ }^{1}$, K. Wakabayashi ${ }^{1}$, T. Kasama ${ }^{1}$, M. Takami $^{2,3}$ T. Isozaki'. 'Showa University School of Medicine, Division of Rheumatology, Department of Medicine, Tokyo, Japan; ${ }^{2}$ Showa University School of Dentistry, Department of Pharmacology, Tokyo, Japan; ${ }^{3}$ Showa University School of Medicine, Pharmacological Research Center, Tokyo, Japan

Background: Hepatocyte growth factor (HGF), originally discovered as a mitogen of hepatocytes, binds to receptor-tyrosine kinase c-Met and has been shown to be a multi-functional cytokine that promotes processes such as cell proliferation, survival, differentiation, migration, and angiogenesis ${ }^{1}$. Since HGF/c-Met signaling also leads to tumorigenesis and cancer invasion, that has recently attracted attention as a target for anticancer agents ${ }^{2}$. However, in reports of rheumatoid arthritis (RA), though anti-inflammatory and antiangiogenic mechanisms related to $\mathrm{HGF} / \mathrm{c}-$ Met signal inhibition have been reported, the role of HGF in RA bone destruction through monocyte migration remains unclear ${ }^{3}$. Objectives: To determine the expression of HGF in RA biological fluids, the role it plays in monocyte migration and the therapeutic effect of a savolitinib, a specific c-Met inhibitor, in arthritis model mice.

Methods: HGF/c-Met expression in serum, synovial fluid (SF), and synovial tissues (STs) obtained from RA patients and control subjects, as well as RA fibroblast-like synoviocytes (FLSs) was evaluated by ELISA and immunostaining. To determine the function of HGF in RA SFs, we preincubated RA SFs with a neutralizing anti-HGF antibody and measured the ability of these SFs to induce the human acute monocytic leukemia cell line (THP-1) chemotaxis. Additionally, examinations of SKG mice treated with savolitinib $(2.5 \mathrm{mg} / \mathrm{kg} /$ day $)$ for 4 weeks were conducted
Results: HGF level in serum from RA patients was significantly higher as compared to the controls $(930 \pm 97$ vs. $476 \pm 97 \mathrm{pg} / \mathrm{mL}, \mathrm{p}<0.01)$ and decreased by drug treatment for 24 weeks $(1147 \pm 284$ vs. $539 \pm 160 \mathrm{pg} / \mathrm{mL}, \mathrm{p}<0.05)$ Additionally, HGF level in SF from RA patients was higher as compared to SF from osteoarthritis patients $(1632 \pm 366$ vs. $566 \pm 140 \mathrm{pg} / \mathrm{mL}, \mathrm{p}<0.05)$. HGF and c-Met expressions were also noted in RA STs. Stimulation of RA-FLS with TNF-a increased HGF/c-Met expression in a concentration-dependent manner, and c-Met signal inhibition by SU11274 suppressed production of fractalkine/ CX3CL1, CXCL16, and MIP-1a/CCL3 (mean 50\%, 56\%, 90\%, respectively) When HGF was removed by immunoprecipitation, migration of THP-1 in RA-SF was suppressed (mean 23\%). In SKG mice, savolitinib significantly suppressed ankle bone damage on $\mu \mathrm{CT}$, with an associated reduction in number of tartrate-resistant acid phosphatase-positive osteoclasts.

Conclusion: HGF is produced by inflammation in synovium associated with RA, and then activates monocyte migration to synovium tissue and promotes bone destruction through its own chemotactic effect as well as enhanced chemokine production. These results indicate that a strategy that targets c-Met signaling may be important for resolving bone destruction in RA.

References:

[1] Nakamura T, Nishizawa T, Hagiya M, Seki T, Shimonishi M, Sugimura A Tashiro K, Shimizu S. Molecular cloning and expression of human hepatocyte growth factor. Nature. 1989 Nov 23;342(6248):440-3

[2] Lee D, Sung ES, Ahn JH, An S, Huh J, You WK. Development of antibody-based c-Met inhibitors for targeted cancer therapy. Immunotargets Ther. 2015 Feb 9;4:35-44

[3] Koch AE, Halloran MM, Hosaka S, Shah MR, Haskell CJ, Baker SK, Panos RJ, Haines GK, Bennett GL, Pope RM, Ferrara N. Hepatocyte growth factor A cytokine mediating endothelial migration in inflammatory arthritis. Arthritis Rheum. 1996 Sep;39(9):1566-75

Disclosure of Interests: None declared

DOI: 10.1136/annrheumdis-2020-eular.3410

\section{SAT0006 SIMULTANEOUS ANALYSIS OF ANTI-CCP RHEUMATOID FACTOR, ANTI-PAD4 AND ANTI- CARBAMYLATED PROTEIN ANTIBODIES REVEALS INTERACTION EFFECTS WITH RESPONSE TO ANTI- TNF THERAPY IN RHEUMATOID ARTHRITIS}

A. Julià ${ }^{1}$, M. Lopez Lasanta ${ }^{1}$, F. Blanco ${ }^{2}$, A. Gómez ${ }^{1}$, I. Haro ${ }^{3}$, A. J. Mas ${ }^{4}$, A. Erra ${ }^{1}$, M. L. García Vivar ${ }^{5}$, J. Monfort ${ }^{6}$, S. Sánchez Fernandez ${ }^{7}$, I. GonzálezÁlvaro $^{8}$, M. Alperi-López ${ }^{9}$, R. Castellanos ${ }^{10}$, A. Fernandez-Nebro ${ }^{11}$, C. Diaz Torne $^{12}$, N. Palau ${ }^{13}$, R. M. Lastra ${ }^{1}$, J. Lladós ${ }^{1}$, R. Sanmarti ${ }^{10}$, S. Marsal ${ }^{1} .{ }^{1}$ Vall d'Hebron Research Institute, Rheumatology Research Group, Barcelona, Spain; ${ }^{2}$ INIBIC-Hospital Universitario A Coruña, Rheumatology Department, $A$ Coruña, Spain: ${ }^{3}$ IQAC-CSIC, Unitat de Síntesi i Aplicacions Biomèdiques de Pèptids, Barcelona, Spain; ${ }^{4}$ Hospital Universitario Son Llàtzer, Rheumatology Department, Palma de Mallorca, Spain; ${ }^{5}$ Hospital Universitario Basurto, Rheumatology Department, Bilbao, Spain; ${ }^{6}$ Hospital del Mar, Rheumatology Department, Barcelona, Spain; ${ }^{7}$ Hospital General La Mancha Centro, Rheumatology Department, Ciudad Real, Spain; ${ }^{8}$ Hospital Universitario La Princesa, Rheumatology Department, Madrid, Spain; ${ }^{9}$ Hospital Universitario Central de Asturias, Rheumatology Department, Oviedo, Spain; ${ }^{10}$ Fundació Clínic per a la Recerca Biomèdica, Rheumatology Department, Barcelona, Spain; ${ }^{11}$ Hospital Regional Universitario de Málaga, Universidad de Málaga, Rheumatology Department, Málaga, Spain; ${ }^{12}$ Hospital de la Santa Creu i Sant Pau, Rheumatology Department, Barcelona, Spain; ${ }^{13}$ Vall d'Hebron Research Institute, Rheumatology Research Group, Barcelona, Spain

Background: Blocking of the Tumor Necrosis Factor (TNF) activity is a successful therapeutic approach for 2 out of 3 Rheumatoid Arthritis patients. Identifying the patients that will not respond to this therapeutic approach is a major translational goal in RA. Association of seropositivity to rheumatoid factor (RF) or anti-cyclic-citrullinated antibodies (anti-CCP) with anti-TNF response has proven inconclusive, suggesting that other yet unexplored biomarkers could be more informative for this goal.

Objectives: We tested the association of two recently introduced biomarkers in RA: anti-carbamylated protein antibodies (anti-CarP) and anti-peptidylarginine deiminase type 4 (anti-PAD4).

Methods: A prospective cohort of $n=80$ RA patients starting anti-TNF therapy was recruited and levels for all four autoantibodies -RF, anti-CCP, anti-CarP and anti-PAD4- were measured at baseline. The change in DAS28 score between baseline and week 12 of therapy was used as the clinical endpoint.

Results: Single marker-analysis showed no significant association with drug response. However, when testing for interactions between autoantibodies, we found highly significant associations with drug response. Anti-CCP and RF showed a positive interaction with the response to anti-TNF therapy $(P=0.00068)$ and anti-PAD4 and antiCarP titers showed a negative interaction with the clinical response at week $12(\mathrm{P}=0.0062)$. Using an independent retrospective sample 
( $n=199$ patients), we validated the interaction between anti-CCP and RF with the clinical response to anti-TNF agents. ( $P=0.044)$.

Conclusion: The results of this study show that interactions between antibodies are important in the response to anti-TNF therapy and suggest potential pathogenic relationships.

Acknowledgments : We would like to thank the clinical researchers and patients participating in the IMID Consortium for their collaboration

Disclosure of Interests: Antonio Julià: None declared, Maria Lopez Lasanta: None declared, Francisco Blanco: None declared, Antonio Gómez: None declared, Isabel Haro: None declared, Antonio Juan Mas: None declared, Alba Erra: None declared, $\mathbf{M}^{\mathbf{a}}$ Luz García Vivar: None declared, Jordi Monfort: None declared, Simon Sánchez Fernandez: None declared, Isidoro González-Álvaro Grant/research support from: Roche Laboratories, Consultant of: Lilly, Sanofi, Paid instructor for: Lilly, Speakers bureau: Abbvie, MSD, Roche, Lilly, Mercedes Alperi-López: None declared, Raúl Castellanos: None declared, Antonio Fernandez-Nebro: None declared, Cesar Diaz Torne: None declared, Núria Palau: None declared, Raquel M Lastra: None declared, Jordi Lladós: None declared, Raimon Sanmarti: None declared, Sara Marsal: None declared DOI: 10.1136/annrheumdis-2020-eular.3801

\section{SAT0007 BLOCKING HISTAMINE-RELEASING FACTOR/ TRANSLATIONALLY CONTROLLED TUMOR PROTEIN (HRF/TCTP) ATTENUATES AGGRESSIVENESS OF FIBROBLAST-LIKE SYNOVIOCYTES AND AMELIORATES COLLAGEN-INDUCED ARTHRITIS IN RHEUMATOID ARTHRITIS}

M. Kim ${ }^{1}$, Y. Choe ${ }^{1}$, H. Lee ${ }^{1}$, Y. H. Cheon ${ }^{1}$, S. I. Lee ${ }^{1} .{ }^{1}$ Gyeongsang National University Hospital, Department of Internal Medicine, Jinju, Korea, Rep. of (South Korea)

Background: Histamine-releasing factor/translationally controlled tumor protein (HRF/TCTP) stimulates cancer progression and allergic responses. Increased expression of HRF/TCTP occurs in joints of rheumatoid arthritis (RA) patients, but the role of HRF/TCTP in RA remains undefined

Objectives: In this study, we explored the pathogenic significance of HRF/TCTP and evaluated therapeutic effects of HRF/TCTP blockade in RA.

Methods: HRF/TCTP transgenic (TG) and knockdown (KD) mice with collagen-induced arthritis ( $\mathrm{CIA})$ were used to determine experimental phenotypes of RA. HRF/TCTP levels were measured in sera and joint fluids in patients with RA and compared to those with osteoarthritis, ankylosing spondylitis, Behcet disease, and healthy controls. HRF/TCTP expression was also assessed in synovium and fibroblast-like synoviocytes (FLS) obtained from RA or OA patients. Finally, we assessed effects of HRF/TCTP and dimerized HRF/TCTP binding peptide-2 (dTBP2), an inhibitor of HRF/TCTP, in RA-FLS and CIA mice. Results: Our clinical, radiological, histological, and biochemical analyses indicate that inflammatory responses and joint destruction were increased in HRF/ TCTP TG mice, and decreased in KD mice compared to wild-type littermates. HRF/TCTP levels were higher in sera, synovial fluid, synovium, and FLS of patients with RA than in control groups. Serum levels of HRF/TCTP correlated well with disease activity in RA. Tumor-like aggressiveness of RA-FLS was exacerbated by HRF/TCTP stimulation and ameliorated by dTBP2 treatment. dTBP2 exerted protective and therapeutic effects in CIA mice, and had no detrimental effect in a murine tuberculosis model.

Conclusion: Our results indicate that HRF/TCTP represents a novel biomarker and therapeutic target for diagnosis and treatment of RA.

References: N/A

Acknowledgments : National Research Foundation of Korea

Korea Health Industry Development Institute

Disclosure of Interests: None declared

DOI: 10.1136/annrheumdis-2020-eular.5088

\section{SAT0008 INDIVIDUAL FUNCTIONS OF THE HISTONE- ACETYLTRANSFERASES CBP AND P300 IN REGULATING THE INFLAMMATORY RESPONSE BY AFFECTING HISTONE ACETYLATION AND MRNA STABILITY}

M. Krosel ${ }^{1,2}$, M. Gabathuler ${ }^{2}$, K. Walker ${ }^{2}$, M. Tomsic ${ }^{1}$, O. Distler ${ }^{2}$, C. Ospelt $^{2}$, K. Klein ${ }^{2} .{ }^{1}$ Department of Rheumatology, University Medical Centre Ljubljana, Ljubljana, Slovenia; ${ }^{2}$ Center of Experimental Rheumatology, Department of Rheumatology, University Hospital Zurich, Zurich, Switzerland

Background: Prolonged TNF-induced H3K27 acetylation (H3K27ac) and increased mRNA stability in rheumatoid arthritis (RA) synovial fibroblasts (SF) are leading to a sustained inflammatory response. Underlying enzymes coordinately regulating these pathways have not been identified so far. The histone acetyltransferases cAMP-response element binding protein binding protein
(CBP) and p300 are writers of activating H3K27ac marks and close homologues with widely accepted redundant functions.

Objectives: To analyze individual functions of CBP and p300 in regulating the inflammatory response of RA SF.

Methods: SF were isolated from patients with RA undergoing joint replacement surgery. The expression of CBP and p300 was silenced by transfection of antisense LNA gapmeRs $(12.5 \mathrm{nM})$. SF were stimulated with TNF $(10 \mathrm{ng} / \mathrm{ml})$ for $24 \mathrm{~h}$. Actinomycin D $(10 \mu \mathrm{g} / \mathrm{ml})$ was added $4 \mathrm{~h}$ after TNF-treatment for $2 \mathrm{~h}$ and $4 \mathrm{~h}(\mathrm{n}=3)$ to test mRNA stability. Transcriptomes were determined by RNA-seq (Illumina NovaSeq 6000, $n=6$ ). We mapped raw reads from RNA-seq reference genome using STAR. Counts for genes were obtained using Feature counts. We searched for differential expression genes (DEG) across experimental conditions using general linear models $(\mathrm{g} / \mathrm{m})$ implemented in 'edgeR' package of $\mathrm{R}$. Significantly affected genes $( \pm$ fold change $>1.5$, FDR $<0.05$, top 3000 genes included) entered pathway enrichment analysis for Gene Ontology (GO) biological process, and KEGG pathways in DAVID. Changes in the mRNA $(n=12-14)$ and protein expression $(n=6-12)$ were confirmed by quantitative Real-time PCR and ELISA. The levels of activating histone marks H3K27ac and nuclear localization of p50 and p65 were analyzed by Western blotting.

Results: DEG revealed that silencing of p300 affected the expression of 6026 and 5138 genes in unstimulated and stimulated SF, respectively. In contrast only 285 and 1911 genes were affected by CBP silencing in unstimulated and stimulated SF, respectively. In TNF-stimulated SF, pathway enrichment analysis of DEG revealed a key role of $\mathrm{CBP}$ in regulating the "type I interferon signaling pathway" $\left(p=2.12 \times 10^{-6}\right)$. Both, silencing of CBP and $p 300$ regulated genes enriched in the "TNF signaling pathway" (CBP: $p=0.005 ; p 300: p=0.031)$. In contrast to CBP silencing that had anti-inflammatory effects, silencing of p300 had pro-and anti-inflammatory effects. ELISA experiments suggested that silencing of CBP reduced the secretion of IL6 $(p<0.01)$, CCL2, CXC3L1 $(p<0.05)$, and CXCL12 $(p<0.001)$. Silencing of $p 300$ reduced the secretion of CCL2 $(p<0.001)$ and CXC3L1 $(p<0.05)$ but increased the expression of IL8 $(p<0.001)$ and CXCL2 $(p<0.05)$. Western blotting revealed that neither CBP, nor p300 silencing affected the nuclear expression of the NF-kB subunits p65 and p50. Silencing of p300 reduced the levels of H3K27ac by $30 \%$ in unstimulated SF, and by $61.4 \%(p<0.05)$ in presence of TNF. In addition to regulating H3K27ac, silencing of p300 regulated the expression of TNF-induced cytokines by increasing the mRNA stability of IL8, IL6 and CCL2 mRNA but not of CXCL2. Silencing of CBP reduced $\mathrm{H} 3 \mathrm{~K} 27 \mathrm{ac}$ by $43.5 \%$ only in presence of TNF and did not affect TNF-induced mRNA stability of cytokines. This is in line with the enrichment of the GO biological process "regulation of mRNA stability" $\left(p=2.61 \times 10^{-8}\right)$ being enriched only after silencing of p300.

Conclusion: Our results suggested that p300 is the major writer for H3K27ac marks in SF. Additionally, p300 regulated cytokine expression by affecting mRNA stability in a target-specific manner. We identified overlapping and distinct functions for CBP and p300 in regulating the inflammatory response of SF.

Disclosure of Interests: Monika Krosel: None declared, Marcel Gabathuler: None declared, Kellie Walker: None declared, Matija Tomsic: None declared, Oliver Distler Grant/research support from: Grants/Research support from Actelion, Bayer, Boehringer Ingelheim, Competitive Drug Development International Ltd. and Mitsubishi Tanabe; he also holds the issued Patent on mir-29 for the treatment of systemic sclerosis (US8247389, EP2331143)., Consultant of: Consultancy fees from Actelion, Acceleron Pharma, AnaMar, Bayer, Baecon Discovery, Blade Therapeutics, Boehringer, CSL Behring, Catenion, ChemomAb, Curzion Pharmaceuticals, Ergonex, Galapagos NV, GSK, Glenmark Pharmaceuticals Inventiva, Italfarmaco, iQvia, medac, Medscape, Mitsubishi Tanabe Pharma, MSD, Roche, Sanofi and UCB, Speakers bureau: Speaker fees from Actelion, Bayer, Boehringer Ingelheim, Medscape, Pfizer and Roche, Caroline Ospelt Consultant of: Consultancy fees from Gilead Sciences., Kerstin Klein: None declared

DOI: 10.1136/annrheumdis-2020-eular.3244

\section{SAT0009 \\ ROLE OF EC-18 IN AUTOIMMUNE ARTHRITIS AND INTERSTITIAL LUNG DISEASE IN CURDLAN- ADMINISTERED SKG MICE}

E. J. Lee ${ }^{1}$, D. H. Kim ${ }^{1}$, J. H. Lee ${ }^{1}$, S. J. Choi ${ }^{1}$, S. H. Nam ${ }^{1}$, J. S. Oh${ }^{2}$, E. J. Chang ${ }^{3}$, S. Hong ${ }^{1}$, C. K. Lee ${ }^{1}$, B. Yoo ${ }^{1}$, Y. G. Kim ${ }^{1} .{ }^{1}$ University of Ulsan College of Medicine, Asan Medical Center, Division of Rheumatology, Department of Medicine, Seoul, Korea, Rep. of (South Korea); ${ }^{2}$ Asan Medical Center, Department of Biomedical Informatics, Seoul, Korea, Rep. of (South Korea); ${ }^{3}$ University of Ulsan, Asan Medical Center, Department of Biomedical Science, College of Medicine, Seoul, Korea, Rep. of (South Korea)

Background: Although the mortality of patients with rheumatoid arthritis (RA) for which interstitial lung disease (ILD) is one of the major contributors, has still not decreased, new target therapies for RA have shown good response in peripheral arthritis. EC-18 (acetylated diacylglycerol 1-palmitoyl-2-linoleoyl-3acetyl-rac-glycerol) is a mono-acetyl-diglyceride that has been isolated from the 